\title{
PERGESERAN PERAN BAHASA INDONESIA
}

\author{
The Shifted Role of Indonesian Language
}

\author{
Fatimah Djajasudarma \\ Universitas Padjadjaran
}

\begin{abstract}
Abstrak
Pergeseran peran bahasa Indonesia dalam penelitian ini dikaitkan dengan peran dan fungsi bahasa Indonesia dalam bidang ekonomi atau bisnis, dan orang, atau lainnya. Perubahan bahasa berarti perubahan budaya. Kata-kata pinjaman akan menyebabkan pergeseran peran bahasa Indonesia oleh bahasa asing akibat kemunculan budaya global di Indonesia. Pergeseran peran bahasa Indonesia berhubungan dengan kehidupan sosial dalam hal penginternasionalan budaya. Bahasa Inggris akan menguasai seluruh dunia di masa globalisasi karena bahasa Inggris adalah bahasa dunia yang digunakan oleh seluruh negara saat melakukan kerja sama. Hal ini menimbulkan banyak hambatan bagi Indonesia untuk mempertahankan bahasa dan budaya mereka. Penelitian ini membahas pergeseran kata-kata Indonesia oleh kata-kata Inggris, terutama dalam bidang bisnis dan nama orang akibat budaya pembaratan dan penginternasionalan yang dipandang memiliki status sosial yang lebih tinggi. Penelitian ini menggunakan data deskriptif dan pendekatan determinisme linguistik dalam kaitannya dengan ide pikiran dan budaya karena bahasa berhubungan erat dengan budaya. Kemunculan kosakata baru menandakan keberadaan hal baru dalam budaya (Humboldt, 1789-1835). Ide Humboldt nerupakan pemicu penelitian dan data yang ada dianalisis berdasarkan teori Sapir-Whorf (1956), Mahyuni (2007), Samuel (2008), Johnson (2000), Searl (1998), dan Djajasudarma (2009).
\end{abstract}

Kata kunci: pergeseran, peran, bahasa Indonesia, kata pinjaman

\begin{abstract}
The shifted role of bahasa Indonesia (BI) in this study due to the role and functions of BI on economic or business fields, and person, or other things. Changing of language means changing of culture. Loanwords will caused the shifted role of BI with foreign language due to the appearance of global culture in Indonesia. The shifted role of BI relates with sosial life as internationalization of culture. English will occupy the whole world in globalization, because English is the world language for every country to cooperate. Most cooperations relate with the need for economic and /or businesses. There many constrains for Indonesia to stand their language and culture because of that situation. This study on the case of Indonesian words shifted by English words especially on business and the name of person due to westernize or internationalized culture with preserved it has a hgher social status. The descriptive data used in this study and linguistic determinism approach used too in relations with the idea of mind and culture, because language has closed relation with culture. The appearance of new vocabulary sign the existence of new item in culture (Humboldt, 17891835). The idea of Humboldt as a trigger in this study and the data analyze due to the suggestion of Sapir-Whorf (1956), Mahyuni (2007), Samuel (2008), Johnson (2000), Searl (1998), and Djajasudarma ( 2009).
\end{abstract}

Keywords: shifting, role, Indonesian language, loan words 


\section{PENDAhUluan}

Semula pinjaman kosakata terjadi karena kontak budaya, kemudian muncul kosakata yang semula dipinjam. Lama-lama kosakata itu dimiliki, dan tidak akan dikembalikan oleh bahasa penerima (resipien). Bahasa donor (sumber pinjaman) di dalam bahasa Indonesia, antara lain bahasa Sansekerta, Arab, Cina, Belanda, Inggris, bahkan Portugis (Djajasudarma, 2004). Bahasa Indonesia menjadi bahasa resipien dari bahasa-bahasa Nusantara, misalnya kata nyeri 'pain/..ache' bahasa Inggris, kata tersebut berasal dari bahasa Sunda 'sakit bagian tubuh tertentu' yang berbeda dari kata sakit bahasa Indonesia. Bahasa Sansekerta lebih dominan di dalam nama-nama ruangan atau bangunan, bahasa Arab di bidang keagamaan dan istilah-istilah tertentu, serta tata nama manusia. Bahasa Belanda dominan pada zaman penjajahan, dan bahasa Inggris dominan di bidang ilmu pengetahuan terutama untuk istilah teknologi. Tetapi, di dalam tata nama anak-anak muda dapat diperhatikan pergeserannya (nama yang dikenal sebagai asal daerah menjadi tidak dikenal dan bergeser ke barat mengikuti budaya barat, misalnya kita tahu asal orang yang bernama Inem berasal dari Jawa, dan nama makanan' terutama nama-nama Indo yang kemudian ditiru (karena memiliki gengsi sosial tertentu) oleh keluarga tertentu. Hal tersebut mengakibatkan peran bahasa Indonesia (BI) tergeser oleh bahasa asing (BA) terutama bahasa Inggris dalam tata nama (baik orang maupun tempat-tempat bisnis/perdagangan/toko-toko).

Kata dapat dipinjam dengan bebas dalam setiap kontak budaya, tetapi tidak sebebas abu yang berterbangan di angkasa. Kata yang dipinjam disesuaikan dengan diksi yang sesuai dengan komunikasi, terutama bagi kata pinjaman yang menyangkut unsur sosial budaya (memiliki dampak terhadap kehidupan sosial-budaya). Weinreich (1965) memberikan sejumlah alasan mengapa terjadi kata pinjaman, kemudian dikutip oleh Taber (1979); Appel dan Pieter Muysken (1988). Alasan tersebut berupa: (1) melalui pengaruh budaya; (2) kosakata penutur asli yang jarang digunakan, kemudian hilang dan diganti dengan kata pinjaman dari bahasa asing; (3) dua kata dari penutur asli yang mirip bunyinya, dan diganti salah satunya dengan kata pinjaman dari bahasa asing untuk mengatasi ketaksaan; (4) ada kebutuhan yang konstan untuk sinonim kata yang mempengaruhi; (5) melalui pinjaman pembeda semantik baru yang memungkinkan; (6) kata yang mungkin diambil dari bahasa yang berstatus rendah dan digunakan secara peyoratif; dan (7) kata yang mungkin diperkenalkan hampir tidak disadari melalui masyarakat bilingual (lihat pula Djajasudarma, 2009).

Salah satu wujud terjadinya kosakata serapan yang dapat dikemukakan di sini selain yang diungkapkan Weinreich, 1965; Taber, 1979; Appel dan Piter Muysken, 1988, Djajasudarma, 2009 adalah kata yang diserap berdasarkan bunyinya (fonetis), atau diserap utuh sebagai importation seperti pada contoh: meeting 'rapat'/'pertemuan'; shooting (mis., dalam perfilman 'to shoot a film 'membuat film'); acting (misal, dalam acting is a wellpaid profession' Bermain sandiwara/film adalah pekerjaan yang penghasilannya baik'), kemudian ada launching, delete, cursor, amulet, conditioner, cleansing milk. Proses linguistis penyerapan bermacam-macam pula, ada yang secara fonetis dari lafal, seperti pada system 'sistem'; absent, absen'; computer komputer', dan bagaimana dengan lafal [bus] dalam bahasa Indonesia?

Dalam hubungan bahasa Indonesia dengan bahasa Melayu Malaysia dapat digunakan dengan memanfaatkan mutual intelligibility'saling mengerti sebagai akibat bahasa serumpun (genetis). Ketidaksesuaian makna di antara kedua bahasa akan dialihkan ke dalam bahasa Inggris sebagai mediator atau sebagai bahasa explanatory. Kosakata bahasa IndonesiaMalaysia dalam kerja sama serantau dapat diteliti melalui sosiolinguistik, yang cenderung menunjukkan gejala, antara lain; (1) konvergensi (keadaan menuju satu titik temu) gradual 
sebagai akibat hubungan yang terus-menerus; (2) pengaruh budaya; (3) pinjaman leksikal; (4) refleksifikasi (di luar kesadaran) secara dratis; (5) pemerolehan bahasa dan pengaruh campuran; (6) tiruan dalam pola bahasa yang berstatus (prestige language pattern) (Appel dan Pieter Muysken, 1998, Djajasudarma, 1996). Kosakata dari Melayu tidak dikatakan sebagai pinjaman tetapi merupakan kesamaan dan perbedaan dalam perkembangannya. Kedua bahasa berpisah karena sejarah dan politik. Dalam perkembangannya kedua bahasa menunjukkan persamaan, pergeseran, dan perbedaan kosakata. Persamaan dipahami sebagai aibat dari bahasa serumpun (genetis), asal sama; pergeseran dipahami sebagai perkembangan dari asal bahasa yang sama dengan penyesuaian lingkungan masing-masing; dan perbedaan dipahami sebagai akibat lingkungan (budaya) atau perkembangan politik yang berbeda (Djajasudarma, 1996).

\section{Hasil dan Pembahasan \\ Pergeseran Peran Bahasa Indonesia}

Pergeseran peran bahasa Indonesia dapat diamati melalui tata nama baik orang maupun tempat bisnis (pertokoan/perdagangan) yang semula kosakata bahasa Indonesia berperan dalam tata nama sekarang peran tersebut tergeser oleh kosakata bahasa Inggris. Bahasa bersifat observable oleh karena itu munculnya kosakata baru menandakan munculnya budaya baru. Pergeseran peran BI identik dengan pergeseran budaya dalam hal ini dipahami atau diamati dari perkembangan kosakata melalui tata nama yang bergeser karena pengaruh budaya global. Budaya global yang cenderung menggambarkan penamaan ke arah westernized 'membarat'. Studi bahasa pada dasarnya merupkan studi peristiwa budaya. Melalui bahasa manusia menunjuk dunianya. Dunia ini penuh dengan nama-nama yang diberikan oleh manusia. Manusia tidak hanya memberi nama tetapi memberi makna pula pada nama tersebut.

Nama merupakan kata-kata yang menjadi label setiap makhluk, benda, aktivitas, dan peristiwa di dunia ini. Nama-nama ini muncul akibat dari kehidupan yang kompleks dan beragam, alam sekitar manusia berjenis-jenis. Kadang-kadang manusia sulit memberikan label satu per satu, akbatnya muncul nama kelompok. Dalam kehidupan sehari-hari ada kata yang mudah dihubungkan dengan acuannya, ada pula yang sulit dan tidak mengacu kepada sesuatu yang konkret. Tata nama dapat terjadi pada nama benda yang kemudian bergeser, misalnya dari alat pemancar (terhubung dengan kata pinjaman dari bahasa Inggris secara utuh , break ... break.... break - apakah padanan bahasa Indonesianya?), kemudian dengan radio (broadcast 'siaran'); televisi (breaking news ...). Di samping itu tata nama di setiap daerah berbeda karena lingkungan budaya yang berbeda. Misalnya untuk menyebut kata padi, bahasa Sunda dengan pare, tetapi di Gorontalo menjadi pale. Jadi apakah hubungan nama dengan benda atau acuannya? Menurut Plato (429-348 SM) ada hubungan hayati antara nama dan benda (kata-kata merupkana nama-nama sebagai label dari benda-benda atau peristiwa). Plato sendiri mempertanyakan apakah pemberian nama kepada benda itu sewenang-wenang atau dengan perjanjian; apakah nama berdasarkan faktor sukarela atau dengan perjanjian semua pihak? Jawaban Plato ada di dalam Cratylous. Lalu, Aristoteles (384-322 SM) menyatakan bahwa pemberian nama adalah soal perjanjian (bukan berarti dahulu ada sidang nama untuk sesuatu).

Nama biasanya berasal dari seseorang (ahli, penulis, pengarang, pemimpin Negara, atau masyarakat, baik melalui media massa elektronika maupun majalah dan koran). Perhatikanlah kata negosiasi 'perundingan' yang muncul pada saat perang Argentina tahun 1982, di Indonesia kata tersebut masuk melalui 'importasi' menggantikan perundingan. Kata yang sama dari peristiwa tersebut muncul kata malvinas, karena pada saat perang Inggris-Argentina itu memperebutkan malvinas, ini pun "diimpor" ke Indonesia menjadi 
akronim dari 'malu-malu tapi ganas', dan di Bandung sendiri menjadi nama makanan baso malvinas atau nama minuman bajigur malvinas. Pergeseran terjadi karena lingkungan budaya (Kata-kata tersebut muncul dari tokoh Inggris pada saat itu, Perdana Mentri Inggris).

Socrates (469-399 SM), guru Plato yang mengemukakan bahwa nama harus sesuai dengan sifat acuan yang diberi nama. Pendapatnya merupakan kebalikan dari apa yang dikemukakan Aristoteles. Pergeseran dalam tata nama di dalam data kata pinjaman ini a.I. dapat difokuskan pada nama diri (manusia), baik itu panggilan maupun acuan. Sistem nama ini bagi masyarakat Sunda terjadi pergeseran dari nama khas Sunda, seperti Toto Suranto, Lili Suherli, Ipah Saripah (seolah-olah ada sebab akibat untuk nama panggilan yang cenderung menjadi dua silabis, diambil dari silabe ultima (akhir) menjadi dua silabis dengan formatif (pengulangan dari silabe ultima). Nama yang dipungut dari bahasa Arab, seperti nama Ahmad, Muhammad, Fatimah (melalui nama panggilan /sapaan menjadi Empat, padahal harusnya dengan satu silabe awal Fat - di dalam bahasa Sunda nama panggilan ini disebut nenehna. Bahasa Sunda adalah bahasa dwisilabis (Robins, 1959; Djajasudarma, 1986), bila nama panggilan satu silabe cenderung dijadikan dua silabe, meskipun berasal dari bahasa Arab, dan fonem inisial /f/ akan diubah menjadi fonem /p/ disesuaikan dengan fonem yang ada dalam bahasa Sunda, fonem /f/ pinjaman dari bahasa Arab. Demikian juga BI dipengaruhi bahasa (budaya) Arab, a.l. kata Alim (tunggal) 'ahli agama' bergeser menjadi 'kalem- pandai' dan Ulama (jamak/plural)' ahli agama', pemakaiannya digabungkan menjadi Alim Ulama 'ahli agama' (dalam BI Jamak), kemudian ada pula yang menjamakan menjadi para alim ulama.

Bahasa daerah mewarnai BI, termasuk budayanya, misalnya panggilan atau sapaan di dalam budaya Sunda pun bergeser dari Ujang (laki-laki) menjadi Boy (dari bahasa Inggris), sedangkan Eu(is)/ E(neng) (perempuan) jarang/hampir tidak digunakan panggilan Girl, tetapi sering digunakan Non sebagai sapaan. Pergeseran tata nama (nama diri) terjadi pula melalui kata pinjaman dari bahasa Barat (a.l. Inggris/Belanda), dapat diperhatikan data berikut: Regina; Theresia; Roger; Willy, Bobby, Moudy Wilhemina, Rionaldo, Julie Estele; ada juga unsur campuran Indonesia dan Barat, a.I. Christian Sugiono; Primus Yustisio; Jessica Iskandar. Dari manakah asal Joanna Alexandria; Agnes Monica; Tamara Bleszynski; Jonathan Frizzy; Sandra Angelia; dan Rowman (data dari Tabloid Infotainmen C \& R). Dapat dibandingkan dengan nama-nama yang cenderung menggambarkan asal seseorang (seperti Inem, dari manakah nama yang mulai dengan Sri atau Siti).

Pergeseran peran BI lebih terlihat di dalam tata nama, yang asalnya dari BI lebih berkembang ke arah berbau bahasa Inggris, baik itu nama toko maupun nama diri (seperti terlihat di atas). Nama toko pakaian bergeser dari toko ke dalam "factory outlet" yang disingkat dengan FO. Nama FO tersebut bermacam-macam disertai dengan daya tarik yang digunakan pula dalam bahasa Inggris, seperti berikut ini.

1. GRANDE - Fashion Galery

2. EPISODE - Fatory Outlet

3. JET SET - Fashion House

4. LEVEL - Factory Outlet - Better Fashion Better Style

5. UP TOWN - Fatory Outlet

Di samping itu, untuk tempat makan ada yang diambil dari bahasa Indonesia atau bahasa Sunda, seperti nama: Panyawangan, Geulis, Bumbu Dapur, Bumbu Desa, dan nama dari bahasa Inggris a.I. Swis Butcher, Royal Dago Hotel \& Restaurant, Coffee \& Lounge, Singapore Quisine. 
Data tersebut dapat dipertimbangkan dari makna kata tersebut secara tersendiri, sebagai berikut.

(1) Kata grande dapat bermakna "besar', utama, 'hebat', 'sangat bagus' atau 'terbagus'. Ada makna maksud di dalam yang tersirat di dalamnya. Nama fashion galery yang dimaksudkan tentunya gabungan antara fashion 'gaya, cara (model)' dan gallery 'serambi'; selasar; anjungan, atau ruangan panjang yang digunakan untuk tujuan tertentu, dalam hal ini digunakan untuk pajangan pakaian yang dijual. Di dalam hal ini budaya global sudah tidak dapat dihindarkan, karena orang hanya akan memahami secara kasat mata dimaknai/dipahami sebagai "toko pakaian yang berhubungan dengan citra FO yang tentunya lebih murah dari boutique " toko pakaian yang menjual pakaian dengan berbagai "fashion" berkualitas prima, karena itu harganya akan lebih mahal daripada FO.

(2) Kata episode 'kisah', 'adegan', 'peristiwa' - yang dimaksudkan di toko tersebut terdapat bermacam-macam pakaian dengan kemungkinan modelnya dihubungankan dengan peristiwa tertentu, makna yang terkandung di dalamnya memiliki kisah dengan episode tertentu. Mana asosiatif yang terkandung dalam kata tersebut mengacu pada model pakaian yang dijual di toko tersebut. Di dalam hal ini ditekankan pula bahwa Episode adalah 'Factory Outlet' jadi harganya tetap lebih murah dari boutique. Bagaimana dibandingkan dengan pakaian yang dijual di Pasar Baru?

(3) Kata jet set 'golongan elit yang kaya dan sering mengembara', jadi FO ini hanya diperuntukan bagi orang-orang elit atau kaya dan sering mengembara dalam belanja. Makna tersebut ternyata tidak diperhatikan bahwa pakaian yang dijual hanya untuk orang-orang kaya, karena kenyataannya banyak yang berbelanja dan tidak dikenal apa kaya atau miskin. Orang-orang yang belanja pun tidak memperhatikan makna tersebut. Sesuaikah bila Jet Set dipadankan dengan FO? Makna FO sendiri adalah Factory ' paberik'; 'kilang' dan Outlet: 1. Saluran keluar; jalan keluar/lepas; 3. Electric: stopkontak. 4. Toko/ tempat penjualan - FO di sini adalah toko/tempat penjualan pakaian dengan berbagai model untuk Jet Set, karena itu ada pernyataan "fashion house" atau sama dengan 'rumah mode', tidak menggunakan FO.

(4) Level di dalam bahasa Indonesia bermakna: 1. tingkat, mutu (untuk pekerjaan); 2. dataran, permukaan; 3. tingkat, 4. waterpos, timbangan datar; 5. derajat, atau dengan verbanya bermakna: 1 . meratakan; 2. menumbangkan; 3. menunjukan; 4. mendatarkan; melontarkan/melancarkan. Semua dapat dipertimbangkan dari makna yang disesuaikan maksudnya yaitu pakaian yang dijual itu memiliki tingkat yang bermutu. Makna asosiatif bila dipertimbangkan dari sifat atau watak yang berbelanja harus berpegang pada "Keep a level head' 'tetaplah tenang' atau Harap berkepala dingin, agar terpilih pakaian yang bermutu. Hal tersebut dihubungkan pula dengan pegangan "Better fashion better style" merupakan kualitas/mutu barang yang ada di FO. 5. Kata up town maknanya bermacam-macam, dapat mengacu kepada : 1.1: of or relating to uptown; 2: UP scale, Fashionable, misalnya (an uptown dress), dan mana kedua adalah the upper part of a town or city; especially: the residential district (Meriam-Wbster's Collgiate Dictionary -Eleventh Edition, 2003: 1376). Acuan yang dipilih dapat berupa produksi pakaian yang berada di bagian atas kota dengan model mutakhir.

Di samping itu, akan ditemukan pula nama Donatello gabungan dari don vt-donned; donning [ME, contr. of do on] muncul pada $14 \mathrm{M}$ bermakna: 1. memakai /barang pakaian, 2. membungkus diri dalam: take on 'memperoleh (sesuatu) atau menjawab tantangan (model); dan Telo dari bahasa Yunani 'end /akhir dari penyisiran/"pencarian"; di samping itu, ada juga blossom 'bunga/ berbunga, banyak makna yang dapat diberikan pada kata tersebut secara asosiatif. Demikian juga ada eternity 'keabadian'/'kekekalan' (adakah barang 
yang kekal?).

Pergeseran budaya terjadi sejak lama dan dapat dievaluasi dari kata pinjaman, dapat diperhatikan pula dari kata pinjaman berikut, seperti di dalam bahasa Indonesia dipengaruhi oleh berbagai negara a.I. : 1. Portugis: Velocipede 'sepeda; Meza 'meja'; 2. Tamil: Santri 'Santri'; 3. Persia: Bazaar 'pasar'; 4. Spanyol: Padre 'Paderi'; 5. Italia: Bancarotto 'bangkrut; 6. Prancis: Unique 'unik; 7. Ibrani: Tabbwur 'tabur'; 8. Yunani: Photos 'foto'. Banyak juga yang dipinjam dari bahasa daerah, antara lain dari bahasa Sunda: Anjang Sono; Nyeri; ajir, agul; jawa: nyata; aku; mampir, malah, dan Minangkabau: kayuh (mengayuh), awak, dan kudapan. Nama sejumlah warung yang dapat membedakan antara pedagang Sunda dari pedagang Jawa, antara lain antara Bubur Kacang Ijo dan Ketan Item dibandingkan dengan Bubur Kacang Hijau dan Ketan Hitam.

Pergeseran peran BI sebagai bahasa nasional dalam hal ini dapat ditelusuri ke belakang, tentang teori yang menyangkut bahasa dan budaya, antara lain berhubungan dengan linguistik determinisme yang berhubungan dengan pengaruh bahasa terhadap pikiran dan budaya (Humboldt, 1769-1835). Bahasa erat hubungannya dengan budaya, sehingga dengan munculnya kosakata baru menandakan munculnya unsur budaya baru yang akan menjadi peneral (trigger) adanya pergeseran budaya. Dengan demikian, untuk masa kini yang cenderung atau dapat dikatakan "mengglobal", tak heran bila nama diri, benda, dan hasil aktivitas manusia (budaya) menggeser budaya asli indigenous knowledge 'kearifan lokal' ke arah budaya global. Selanjutnya Humboldt menggabungkan berbagai bahasa dengan latar belakang filosofis bahwa bahasa adalah satu jenis aksi manusia (sebagai buruh dari manusia), seperti yang dihasilkan oleh unsur internal pikiran, perasaan, keinginan, kepercayaan, dan keputusan. Sejalan dengan ide tersebut dalam BI ada pernyataan bahwa "bahasa digunakan untuk menyatakan pikiran dan perasaan", sangat erat dengan dasar filosofis yang diungkapkan oleh Humboldt tersebut.

Berbicara pergeseran peran BI dari segi sosiolinguistik (kata pinjaman) akan muncul ancangan yang menghubungkan bahasa dan budaya, a.I. Boas (1911) mengembangkan linguistik deterministik untuk menangani fenomena bahasa dari perspektif sosioantropologi. Ide Humboldt dan Boas yang dikembangkan Sapir (1949) yang memandang bahasa sebagai kekayaan manusia yang asli, melalui bahasa manusia mengkomunikasikan ide-gagasan dengan tujuan menghasilkan lambang secara bebas (lihat pula Mahyuni, 2007). Manusia tidak hidup sendirian dalam dunia yang objektif dan juga dalam aktivitas sosial yang dapat dimengerti secara wajar sangat bergantung kepada bahasa tertentu untuk menjadi media ekspresi dari masyarakatnya. Kemudian, ide dari Sapir-Whorf (1956) dikenal dengan semboyan "Bahasa cermin bangsa", bagaimana BI dengan kehidupan global sekarang mampukah kita mempertahankan identitas melalui bahasa dan budaya nasional? Satu tantangan bagi para peneliti bahasa budaya dan atau linguis dalam menangani penelitian kata pinjaman dari bahasa asing, dengan alasan seperti dinyatakan oleh Weinreich (1965) atau Samuel (2008) "Kasus Ajaib Bahasa Indonesia"?

Pergeseran peran BI secara kasat mata dapat terlihat dalam pengayaan kosakata baik bagi unsur budaya yang belum ada maupun unsur tata nama yang memiliki alasan khusus "karena gengsi sosial tertentu". Kontak bahasa sendiri terjadi setiap hari melalui kontak sosial-budaya, dan kontak bahasa pada masa sekarang menjadi lebih kompleks, dan pinjaman kosakata menjadi peristiwa yang biasa. Kontak bahasa diawali dengan kontak budaya dan dapat memperkaya atau mendesak kosakata bahasa penerima. Memperkaya dalam arti istilah sosial-budaya yang belum ada dapat diperkaya dengan istilah yang baru muncul, dipinjam dan tidak akan dikembalikan, sedangkan ada kosakata yang tergeser karena kosakata tersebut dianggap tidak memenuhi pemahaman yang ada atau menjadi usang, arkais, dan/atau kuno . 
Pergeseran peran BI pun terlihat di dalam data tata nama bangsa Indonesia, seperti dinyatakan dalam data. Dari sejak premis Sapir-Whorf yang terkenal bahasa dihubungkan dengan budaya, hipotesis tersebut memerikan pentingnya hubungan antara bahasa dan pikiran (language and thought) yang kemudian diberi argumentasi oleh Whorf (1940) bahwa relativitas linguistik menyatakan bahwa semua pengamat tidak dipandu dengan bukti fisik ke arah gambaran dunia yang sama, kecuali dengan latar belakang linguistik yang sama, atau didapat dengan cara yang sama kemudian disesuaikan.

Pendapat atau ide Humboldt dan Boas kemudian dikembangkan oleh Sapir (1949), tentang hubungan bahasa dengan aktivitas sosial (budaya) disebutkan bahwa manusia tidak hidup sendiri di dalam dunia objektif, dan juga tidak sendirian di dunia aktivitas sosial seperti yang dipahami sekarang, tetapi sangat banyak bergantung pada kemurahan hati bahasa tertentu yang menjadi media ekspresi untuk masyarakat. Premis tersebut kemudian dikenal sebagai hipotesis Sapir-Whorf, hipotesis ini terutama membincangkan orientasi bahasa tertentu dengan penutur ke arah cara tertentu untuk mengetahui, mengerti, mempercayai, dan memandang dunia (Searl, 1979; Mahyuni, 2007: Djajasudarma, 2009).

Di samping masalah empiris yang dipertimbangkan Sapir-Whorf, pernyataan bahwa bahasa bukan merupakan maujud tersendiri, melainkan sebagai kekayaan sosial (Johnson, 2000, Searl, 1998). Meskipun stratifikasi sosial dalam bahasa tidak universal, beberapa bahasa di Indonesia memiliki tingkat tutur, dalam komunikasi, yakni adanya pertimbangan tingkat sosial kawan bicara. Unsur bahasa ini merupakan salah satu unsur budaya dalam hal kosakata pemerkaya/pewarna BI. Bahasa Nusantara berfungsi sebagai bahasa budaya, misalnya dari bahasa Sunda atau Jawa karena keduanya memiliki apa yang disebut undak usuk. Demikian pula kata-kata tabu masuk ke dalam BI. Unsur eufemisme ini mengisi kekosongan yang ada di dalam bahasa Indonesia. Kosakata pinjaman yang berasal dari bahasa Nusantara (daerah) ini mewarnai BI dan sebaliknya dari BI, akan mewarnai bahasa Nusantara, terutama kosakata yang diserap dari bahasa asing ke dalam BI. Kosakata pinjaman itu semula ke arah nasionalisasi, tetapi sekarang ke arah globalisasi (bandingkan mana yang berbau lokal bahasa Sunda dan mana yang lokal antara kata 'berhiber' dengan bermartabat.

Dari perspektif antropologi pergeseran budaya ditandai oleh munculnya kosakata baru dalam BI yang berkaitan erat dengan pinjaman leksikal, seperti dinyatakan oleh Albo (1970), yang membedakan proses subtitusi (bandingkan dengan istilah Haugen importation 'importasi' morfemis dengan subtitusi semantik; dan penambahan kosakata merupakan importasi baik morfemis maupun semantik (Appel dan Pieter Muysken, 1988; Haugen, 1950; Albo, 1970). Dari perspektif tata nama dapat diperhatikan bagaimana bentuk fonologis dan semantik kata pinjaman mempengaruhi bahasa Indonesia.

\section{Simpulan}

Pergeseran peran BI dipertimbangkan dari tata nama, baik nama diri maupun nama benda atau pusat-pusat pertokoan yang benar-benar kasat mata. Pergeseran peran di Indonesia terjadi mulai dari dari bahasa (budaya) lokal - nasional dan ke dalam bahasa (budaya) Internasional. Pergeseran peran ini dapat diamati dari kata pinjaman, seperti dinyatakan para pakar bahasa bahwa dalam pinjaman itu terjadi proses linguistis dan pergeseran budaya. Kata pinjaman terjadi karena (1) melalui pengaruh budaya, karena kontak budaya terjadi setiap hari dengan alat komunikasi bahasa; (2) kosakata penutur 
asli yang jarang digunakan sehingga menjadi kosakata usang, arkhaik, dan kuno; (3) dua kata dari penutur asli yang mirip bunyinya, dan diganti salah satunya dengan kata pinjaman atau tabu diucapkan; (4) ada kepentingan konstan untuk sinonim kata yang mempengaruhi (terutama di bidang istilah tertentu); (5) melalui pinjaman pembeda semantik baru yang memungkinkan karena lingkungan budaya tertentu (misalnya, bagaimana dengan isu dan realestate dari bahasa Inggris?); (6) kata yang mungkin diambil dari bahasa yang berstatus rendah dan digunakan secara peyoratif; dan (7) kata yang mungkin diperkenalkan hampir tidak disadari melalui masyarakat bilingual. Di samping ketujuh gejala tersebut, terdapat pula alasan bila diperhatikan melalui data tata nama diri (manusia) dan toko-toko yang berbahasa pinjaman dari bahasa Inggris dapat dipertimbangkan alasan: (1) globalisai; (2) dari sudut ekonomi mengakibatkan budaya ekonomi baru dalam pasar global, demi efektivitas dalam mencari keuntungan; (3) menyangkut status sosial baik secara go public maupun go internasional, dan bentukan baru karena budaya baru.

Dalam kerja sama serantau kosakata Indonesia-Malaysia cenderung menunjukan gejala a.I. (1) konvergensi (keadaan menuju satu titik temu); (2) pengaruh budaya; (3) pinjaman leksikal; (4) refleksifikasi (di luar kesadaran) secara drastic, (5) pemerolehan bahasa dan pengaruh campuran; (6) tiruan dalam pola bahasa yang berstatus (prestige language pattern). Meskipun ada gejala pinjaman yang sama dengan alasan yang telah disebutkan, tetapi tidak dikatakan kosakata pinjaman dengan alasan serumpun. Persamaan dianggap sebagai akibat dari bahasa serumpun (genetis); perbedaan/pergeseran dianggap sebagai perkembangan dari bahasa asal yang sama, disesuaikan dengan lingkungan (budaya) masing-masing. Peran BI sebagai bahasa resmi, bahasa kenegaraan masih ajeg, tetapi dalam kehidupan sehari-hari secara pragmatis mengalami pergeseran peran terutama dipertimbangkan dari kosakata yang muncul di bidang ekonomi dan istilah-istilah di bidang Iptek. Hal tersebut yang akan mengakibatkan tergesernya peran BI sebagai bahasa nasional.

*) Prof. Dr. Hj. T. Fatimah Djajasudarma, Guru Besar Linguistik-Semantik-Dialektologi Fakultas Sastra Universitas Padjadjaran. 


\section{Daftar Pustaka}

Albo, X. 1970. Social Constrain on Cochabamba QUECHUA. Disertation Series no. 19 Latin American Studies Program. Cornell University. Ithaca, New York: Latin American Studies Program.

Appel, Rene \& Pieter Muysken. 1988. Language contact and Bilingualism. Great Britain: Edward Arnold. A division of Holder \& Stoughton.

Boas, Franz. 1911 (1995)." Introduction to the Handbook of American-Indian Languages", dalam language, Culture, and Society: A Book of Readings. Ben G. Blount (ed.). Waveland Press Inc.

Djajasudarma, T. Fatimah. 1996. "Kosakata Indonesia-Malaysia Serupa Tapi Tak Sama" di dalam Rampak Serantau hlm. 78-88 vol 3. Jakarta: Pusat Bahasa, Depdikbud.

Djajasudarma, T. Fatimah. 2004. "Menyikapi 9 dari 10 Kata Bahasa Indonesia adalah Asing- Alif Danya Munsyr". Makalah Seminar Mengenal Budaya Berbahasa Bangsa Indonesia Melalaui Bahasa Politik dan Bahasa Media. Bandung: Faultas Sastra Universitas Padjadjaran.

Djajasudarma, T, Faimah. 2009. Semantik 1: Makna Leksikal dan Gramatikal. Semantik 2: Pemahaman IImu Makna. Bandung: Refika Aditama. Terbitan pertama tahun 1993; kedua tahun 2007.

Djajasudarma, T. Fatimah, et al. 2009. "Loanwords in Indonesian Language". Makalah Kongres Internasional Masyarakat Indonesia (KIMLI). Malang: 5-7 November 2009.

Haugen, E. 1950. The Analysis of Linguistic Borrowing. Language 26. P. 210-232.

Johnson, L. F. 2000. Speaking Culturally: Language Diversity in the United States. London: Sage Publications.Inc.

Mahyuni. 2007. "Valuing Language and Culture: An Example From Sasak" . dalam Makara Seri Sosial Humaniora. Vol. 11. Desember 2007 No.2. Jakarta: Universitas Indonesia.

Robins, R.H. 1959. "Nominal and Verbal Derivation in Sundanese, dalam lingua 8: p. 337-369.

Samuel, Jerome. 2008. Kasus Ajaib Bahasa Indonesia? Pemodernan Kosakata dan Politik Peristilahan. Terjemahan dari Modernisation lexical et politique terminologique: Le cas de I'Indonesien (Editions Peeters, Paris-Louvain, 2005).

Sapir, E. 1949. "Graduation: A Study in Semantics", dalam D. Mandelbaum (ed.) Selected Writings of Edward Sapir in Language, Culture and Personality. Berkley: University of California Press.

Searl, J, 1979. Expression and Meaning : Studies in the Theory of Speech Acts. Cambridge: Cambridge University Press.

Weinreich, U. 1965. Language in Contact. Findings and Problems. The Hague: Mouton.

Whorf, B.L. 1956. Language, Thought, and Reality, Selected Writings of Benjamin Lee Whorf. J.B. Carroll. 